\title{
Pearl extract protects HaCaT cells from UV radiation-induced apoptosis through mitochondrial pathway regulation
}

\section{Zhixiong Chen}

Zhe jiang OSM Group Deqing Biotechnology Co.,Ltd

jing wang ( $\square$ wangjing@osmbio.com )

Zhejiang University

Anquan Yang

Zhejiang OSM Group Co.,Ltd,.

Lihua Zhang

Zhe jiang OSM Group Co.,Ltd,.

Yaojia Lu

Zhejiang OSM Group Deqing Biological

Jiahuan Mo

Zhejiang OSM Group Deqing Biological Co.,Ltd,.

\section{Min Xie}

Zhejiang OSM Group Co.,Ltd.,

Xinzhong Shen

Zhe jiang OSM Group Co,.Ltd.,

Research

Keywords: pearl extract, ultraviolet, human keratinocyte cell, apoptosis

Posted Date: April 2nd, 2020

DOI: https://doi.org/10.21203/rs.3.rs-20482/v1

License: (c) (1) This work is licensed under a Creative Commons Attribution 4.0 International License.

Read Full License 


\section{Abstract}

Background: Previous studies have demonstrated that pearl extract (PE) promotes wound healing and skin whitening. However, it remains unclear whether PE can inhibit ultraviolet (UV)-photodamage in $\mathrm{HaCaT}$ cells. In this study, an in vitro photoaging cell model was established to observe the effect of PE on UV-induced damage and the apoptosis of HaCaT cells. The aim of this study was to provide a reference for the future development of natural sunscreens.

Results: PE concentrations of 0.1 and $1 \mu \mathrm{g} / \mathrm{mL}$ were considered the most effective and safe concentrations. Compared to that in the control group, superoxide dismutase and glutathione peroxidase activity in the photoaging group was significantly reduced, whereas malondialdehyde and reactive oxygen species content, along with tumour necrosis factor-alpha (TNF-a) and interleukin (IL)-10 mRNA and protein levels, were markedly increased. In contrast, Bcl-2 protein expression was significantly decreased, whereas caspase-3, caspase-9, and Bax protein expression levels were significantly increased. Compared to that in the photoaging group, $\mathrm{HaCaT}$ cell proliferation was significantly increased in the PE group. Both PE concentrations significantly increased superoxide dismutase and glutathione peroxidase activity in cells, reduced malondialdehyde and reactive oxygen species content, decreased TNF-a and IL10 mRNA expression in cells, and reduced TNF- $a$ and IL-10 protein levels in the supernatant. Additionally, Bcl-2 protein expression levels were significantly increased, whereas caspase-3, caspase- 9 , and Bax protein expression levels were significantly reduced by PE treatment.

Conclusions: PE can inhibit UV-induced apoptosis by inhibiting mitochondria-mediated apoptosis and regulating TNF- $a$ and IL-10 expression.

\section{Background}

Human keratinocytes (HaCaT cells) are the main cellular constituent of the epidermis (outermost layer of the skin), accounting for more than $90 \%$ of epidermal cells [1]. Keratinocytes prevent external physical, chemical, and microbial damage and maintain the stability of the internal environment of the body [2]. Additionally, they can protect the skin by absorbing $95 \%$ of the ultraviolet (UV) radiation that reaches the skin [3]. Human keratinocytes participate in various cellular and biological processes, such as apoptosis and inflammation [4]. Damage to human epidermal keratinocytes caused by UV radiation occurs mainly because of the production of reactive oxygen species (ROS) [5], which induce DNA damage, enzymatic activity, and mitochondrial dysfunction, resulting in damage to various cell functions [6]. To maintain the normal function of human epidermal keratinocytes, the skin can be covered by clothing, which reduces UV radiation exposure and oxidative damage [7]. Additionally, antioxidants are effective in reducing oxidative damage [8]. UV-protection activity has been demonstrated in many extracts, which contain various active ingredients, but their chemical components are unclear. Li et al. found that the $50 \%$ ethanol macroporous resin eluate of Eucommia ulmoides effectively protects against UVA and UVB-induced photoaging in HaCaT cells [9]. Han et al. reported that rose water inhibits the UV-induced apoptosis of $\mathrm{HaCaT}$ cells by regulating the nuclear factor-kappa B (NF-kB) nuclear transcription factor pathway [10]. Li 
et al. demonstrated that hesperidin antagonizes the decreased antioxidant enzymatic activity in HaCaT cells caused by UVB and showed photoprotective effects [11].

Pearl powder is used as a traditional Chinese medicine to moisturize the heart, liver, and muscle and slow skin ageing $[12,13]$. Anti-inflammatory and anti-apoptotic properties have also been described $[14,15]$. We previously reported that PE effectively reduces the melanin content in cells by inhibiting the activity of intracellular tyrosinase, suggesting that PE has a whitening effect [16].

However, an inhibitory effect of PE on UV-induced photodamage in HaCaT cells has not been reported. Therefore, in this study, an in vitro photoaging cell model was established to evaluate the effect of PE on UV-induced damage and the apoptosis of UV-irradiated HaCaT cells. Furthermore, we explored the molecular mechanisms involved.

\section{Methods}

\section{Preparation of Pearl Extract (PE)}

PE containing $2.1 \%$ total protein was kindly provided by Zhejiang Osmum Biological Co., Ltd. (Huzhou, China). The freshwater pearls produced by Hyriopsis cumingii were ground to a nanometre scale (10-100 $\mathrm{nm}$ ) and hydrolysed with neutral protease to obtain various amino acids, trace elements, and polypeptides.

\section{Cell Culture and Subgroups}

HaCaT cells (purchased from Shanghai GeFan Biotechnology Co., Ltd., Shanghai, China) were cultured in RPMI-1640 medium supplemented with $10 \%$ foetal bovine serum and $1 \%$ penicillin and streptomycin in $5 \% \mathrm{CO}_{2}$ at $37^{\circ} \mathrm{C}$. Using a biological-inverted microscope, round-shaped newly subcultured HaCaT cells were observed. After $4 \mathrm{~h}$ of culture, the cells began to adhere to the culture plate, and after $24 \mathrm{~h}$ of growth, the cells were completely adherent. The cells were collected during exponential growth for subsequent experiments and were divided into the following subgroups: control group, photoaging cell group (irradiated with $10 \mathrm{~J} / \mathrm{cm}^{2} \mathrm{UV}$ ), and PE + UV group (pre-treated with PE and then irradiated with $10 \mathrm{~J} / \mathrm{cm}^{2}$ UV). According to our previous study, PE was added to the culture medium for $48 \mathrm{~h}$ at different concentrations $(0,0.01,0.1,1$ and $10 \mu \mathrm{g} / \mathrm{mL})$ and then cells were $\mathrm{UV}$ irradiated.

\section{UV Irradiation of Cells}

Prior to UV irradiation, the cells were washed with phosphate-buffered saline (PBS) and covered with a thin layer of PBS. The cells were irradiated in ice-cold plates to eliminate UV thermal stimulation. Monolayers of HaCaT cells in a thin layer of PBS were irradiated with $10 \mathrm{~J} / \mathrm{cm}^{2} \mathrm{UV}$ and incubated with culture medium containing PE for $24 \mathrm{~h}$. 
HaCaT cells $\left(1 \times 10^{5} / \mathrm{mL}\right)$ were cultured in 96 -well plates. Different concentrations of PE $(0,0.01,0.1,1$ and $10 \mu \mathrm{g} / \mathrm{mL}$ ) were added to the cell suspension, and the cells were incubated for $48 \mathrm{~h}$ at $37^{\circ} \mathrm{C}$ in a $5 \%$ $\mathrm{CO}_{2}$ incubator. The cells were irradiated with $10 \mathrm{~J} / \mathrm{cm}^{2} \mathrm{UV}$, whereas control cells were sham irradiated by covering with tin foil. Furthermore, the cells were incubated for $24 \mathrm{~h}$ in a cell incubator at $37^{\circ} \mathrm{C}$ in $5 \% \mathrm{CO}_{2}$. Cell viability was assessed by the CCK8 assay (Jian Cheng Bioengineering Co., Nanjing, China). After the indicated treatments were performed, $10 \mu \mathrm{L}$ of CCK8 was added to each well for $4 \mathrm{~h}$ at $37^{\circ} \mathrm{C}$, and the absorbance of each well was measured using a plate reader at a wavelength of $490 \mathrm{~nm}$. Finally, the concentration of $\mathrm{PE}$ showing a significant protective effect against UV radiation-induced cell damage was selected for further experiments. The experiment was repeated five times.

\section{Assays of Cellular ROS, Glutathione Peroxidase (GSH-Px), Superoxide Dismutase (SOD), and Malondialdehyde (MDA)}

Cells were seeded in 6-well plates $\left(2 \times 10^{4}\right.$ cells/well) and treated with different concentrations of PE $(0.1$ and $1 \mu \mathrm{g} / \mathrm{mL}$ ) for $48 \mathrm{~h}$ prior to UV irradiation. Subsequently, the cell suspensions were collected and assayed for ROS and MDA levels and GSH-Px and SOD activity using assay kits in accordance with the manufacturer's instructions (Jian Cheng Bioengineering Co., Nanjing, China).

\section{Cytokine mRNA Levels}

Total RNA was isolated from HaCaT cells via treatment using an RNAiso Plus kit (TaKaRa Bio, Shiga, Japan) according to the manufacturer's guidelines. For each RT-PCR sample, $1 \mu \mathrm{g}$ of total RNA was added, and the purity of the RNA was determined as the ratio of the optical density reading at $260 \mathrm{~nm}$ relative to that at $280 \mathrm{~nm}$. The ratio of the RNA used for RT-PCR was 1.8 to 2.0. TNF-a, IL-10, and $\beta$-actin mRNA levels were determined by real-time quantitative PCR using a SYBR ${ }^{\circledR}$ Premix Ex Taq ${ }^{\text {TM }}$ Kit (TaKaRa Bio) according to the manufacturer's instructions. cDNA amplification of a specific sequence of human TNF- $\alpha$, IL-10, and $\beta$-actin was performed by PCR using the primer sequences shown in Table 1. PCR was conducted at $95^{\circ} \mathrm{C}$ for $30 \mathrm{~s}$, followed by 40 cycles of $95^{\circ} \mathrm{C}$ for $5 \mathrm{~s}$ and $60^{\circ} \mathrm{C}$ for $34 \mathrm{~s}$ in the StepOne Plus real-time PCR system (Applied Biosystems, Foster City, CA, USA). The qRT-PCR results were analysed and are expressed as the relative mRNA expression of the threshold cycle (CT) value, which was then converted to the fold change. Quantitative real-time RT-PCR assays were performed to detect $\beta$-actin expression and normalize the amount of cDNA in each sample.

\section{Cytokine Protein Expression}

After being treated as indicated for $48 \mathrm{~h}$, the supernatant of each group of cells in the 6-well plate was collected. TNF- $a$ and IL-10 were detected in accordance with the enzyme-linked immunosorbent assay kit instructions (Jian Cheng Bioengineering Co.). The cytokine concentration was measured three times.

\section{Western Blot Analysis}


After appropriate treatment for $48 \mathrm{~h}$, the HaCaT cells were collected using RIPA mixed with phenylmethylsulphonyl fluoride to extract protein (Solarbio Science \& Technology Co., Ltd., Beijing, China). Protein levels were measured by the bicinchoninic acid assay (Jian Cheng Bioengineering Co.). Briefly, $50 \mu \mathrm{g}$ of protein was resolved by $12 \%$ sodium dodecyl sulphate-polyacrylamide gel electrophoresis for $60 \mathrm{~min}$ at $140 \mathrm{~V}$, and the resolved proteins were transferred to a polyvinylidene fluoride membrane for $45 \mathrm{~min}$ at $60 \mathrm{~V}$. The membrane was blocked with $5 \%$ fat-free dried milk powder in TBST ( $1 \times$ Tris buffered saline, $0.1 \%$ Tween-20) at room temperature for $2 \mathrm{~h}$ and incubated with primary antibody diluted 1:1000 in fresh blocking buffer overnight at $4^{\circ} \mathrm{C}$ with gentle shaking. Rabbit anti-caspase-3, rabbit anti-caspase- 9 , rabbit anti-Bcl-2, rabbit anti-Bax, and rabbit anti-actin antibodies were purchased from Cell Signaling Technology, Danvers, MA, USA. Goat anti-rabbit secondary antibodies (Abmart, Shanghai, China) were diluted at 1:8,000 in fresh blocking buffer and incubated with the membranes for $1 \mathrm{~h}$ at room temperature. The membranes were washed five times for $10 \mathrm{~min}$ each in TBST, and the bands were detected using an ECL Plus kit (Solarbio Science \& Technology Co., Ltd.). The membranes were exposed to Tanon 5200 Multi (Tanon Science \& Technology Co., Ltd., Shanghai, China), and TanonImage analysis software was used for quantitative analysis.

\section{Statistical Analysis}

All data are expressed as the mean \pm SD. Experiments were independently repeated at least three times. P $<0.05$ indicated significant differences between the experimental and control groups, which were analysed by one-way analysis of variance. Representative western blots from three independent experiments are shown.

\section{Results}

\section{Effect of PE on the HaCaT Cell Proliferation Rate}

Compared to the blank control, $0.01 \mu \mathrm{g} / \mathrm{mL}$ PE significantly increased cellular proliferation $(\mathrm{P}<0.01$; Fig. 1). PE concentrations of 0.1 and $1 \mu \mathrm{g} / \mathrm{mL}$ showed no obvious effect enhancement, and there was no significant effect on the cellular proliferation rate. In contrast, $10 \mu \mathrm{g} / \mathrm{mL}$ PE significantly inhibited cell proliferation $(P<0.01)$. Therefore, 0.1 and $1 \mu \mathrm{g} / \mathrm{mL}$ PE were used in subsequent experiments.

\section{Effect of PE on the Proliferation Rate of Photoaged HaCaT Cells}

Compared to that of the blank group, the proliferation rate of the model group was significantly reduced $(P<0.01)$, suggesting that UV radiation inhibits cellular proliferation (Fig. 2). Compared to the model group, the 0.1 and $1 \mu \mathrm{g} / \mathrm{mL} P E$ treatment groups had significantly increased cellular proliferation $(P<$ 0.01 ), suggesting that $P E$ protects against photoaging in cells in a concentration-dependent manner.

\section{Effect of PE on Cytokine mRNA Levels}

Total cellular RNA was extracted after UV irradiation, and cDNA for b-actin was used as an internal control. The qRT-PCR results were converted to fold changes. Significantly higher levels of TNF-a (Fig. 3a) 
and IL-10 (Fig. 3b) mRNA were evident in the photoaging group compared to the blank group $(\mathrm{P}<0.01)$. Compared to that in the photoaging group, the TNF-a mRNA expression level in the 0.1 and $1 \mu \mathrm{g} / \mathrm{mL} P E$ treatment groups was decreased significantly in a concentration-dependent manner $(\mathrm{P}<0.05$ and $\mathrm{P}<$ 0.01 , respectively). Similar results were observed for IL-10 mRNA expression $(P<0.05$ and $P<0.01$, respectively), suggesting that PE downregulates TNF-a and IL-10 expression.

\section{Effect of PE on Cytokine Protein Expression}

The levels of IL-10 and TNF-a were measured by enzyme-linked immunosorbent assay. As shown in Fig. 4 , the protein expression levels of IL-10 and TNF-a in the photoaging group were significantly higher than those in the control group (both $\mathrm{P}<0.01$ ). Compared to that in the photoaging group, TNF-a protein expression was significantly reduced in the presence of 0.1 and $1 \mu \mathrm{g} / \mathrm{mL} P E(P<0.05$ and $P<0.01$, respectively), and IL-10 protein levels were similarly reduced $(P<0.05$ and $P<0.01$, respectively), suggesting that $\mathrm{PE}$ decreases the inflammatory response in cells.

\section{Effect of PE on the Antioxidant Indices of UV-Irradiated HaCaT Cells}

The effects of different concentrations of PE on ROS, SOD, GSH-Px, and MDA content in UV-irradiated $\mathrm{HaCaT}$ cells are shown in Fig. 5. Statistical variance analysis revealed that the differences in the measured indices between groups were significant. The activity of GSH-Px and SOD in the photoaging group was significantly lower than that in the control group (both $P<0.01$ ). In the 0.1 and $1 \mu \mathrm{g} / \mathrm{mL} P E$ treatment groups, SOD levels (both $P<0.05$ ) and GSH-Px levels were higher than those in the $(P<0.05$ and $P<0.01$, respectively). Furthermore, ROS and MDA levels in the photoaging group were significantly higher than those in the control group $(P<0.01)$. Compared to the photoaging group, the $0.1 \mathrm{and} 1 \mu \mathrm{g} / \mathrm{mL}$ $P E$ treatment groups had significant decreases $(P<0.05$ and $P<0.01$, respectively) in a concentrationdependent manner.

\section{Effect of PE on Caspase-3, Caspase-9, Bax, and Bcl-2 Protein Expression Levels in HaCaT Cells}

The levels of caspase-3, caspase-9, Bax, and Bcl-2 were measured by western blot analysis (Fig. 6a). Compared to that in the control group, the $\mathrm{Bcl}-2$ protein expression in the photoaging group was significantly decreased $(P<0.05)$, whereas caspase- 3 , caspase- 9 , and Bax protein expression levels were significantly increased $(P<0.01, P<0.05$ and $P<0.05$, respectively; Fig. $6 \mathrm{~b})$. Compared to that in the photoaging group, the Bcl-2 protein expression in the $1 \mu \mathrm{g} / \mathrm{mL} P E$ group was increased significantly $(\mathrm{P}<$ 0.05). In contrast, in the 0.1 and $1 \mu \mathrm{g} / \mathrm{mL} P E$-treated groups, there were significant decreases in caspase-3 $(P<0.05$ and $P<0.01$, respectively), caspase $-9(P<0.05$ and $P<0.05$, respectively), and Bax protein levels (both $P<0.01$ ).

\section{Discussion}

$\mathrm{HaCaT}$ cells reside in the most superficial layer of human skin and are the main target cells of UV radiation [17]. Long-term UV radiation can lead to skin photoaging and even cancer [18]. Apoptosis is the 
gene-regulated process of autonomous and orderly cell death to maintain homeostasis in the internal environment [19]. Because of changes in the internal and external cellular environment, as well as death signalling induction, this process eliminates ageing cells and other cells with potential abnormal growth to maintain homeostasis in the cell population [20]. Apoptosis is mainly controlled by three pathways: mitochondrial signalling, death receptor-mediated signalling, and endoplasmic reticulum-mediated signalling [21]. Apoptosis is closely associated with changes in mitochondrial structure and function. Long-term UV radiation causes excessive ROS accumulation in the cell, which damages DNA and the inner mitochondrial membrane [22], ultimately resulting in the loss of mitochondrial function, lipid peroxidation, proteins, and nucleic acids, and direct promotion of apoptosis [23]. The level of MDA often reflects the degree of lipid peroxidation in the cell and indirectly reflects the degree of cell damage [24]. As such, MDA and SOD assays are often used interchangeably. GSH-Px is an enzyme that is widely found in cells. It catalyses the breakdown of hydrogen peroxide and protects the integrity and function of the cell membrane [25].

As a key pro-inflammatory factor widely distributed in the cell, TNF-a has a variety of biological effects, including mediating inflammation, the immune response, and apoptosis [26]. UV radiation causes an increase in TNF-a protein secretion and total TNF-a expression [27]. Increased TNF-a can accelerate the induction of keratinocyte apoptosis via binding to the corresponding receptor. Additionally, UV radiation causes the increased secretion of TNF-a and IL-10 [28], which in turn promotes apoptosis of UV-irradiated keratinocytes, thus playing an important role in UV-induced skin damage [29].

In the mitochondrial apoptosis pathway, the Bcl-2 protein family plays a very important role, including pro-apoptotic and anti-apoptotic effects [30]; these proteins regulate apoptosis by controlling the permeability of the mitochondrial membrane [31]. The caspase family is a series of cysteine amino acid proteases with similar amino acid sequences and secondary protein structures. Caspase proteins can block the cell cycle, label apoptotic cells, breakdown structural proteins in the cytoskeleton, and inactivate DNA repair enzymes, leading to apoptosis [32]. Under physiological conditions, apoptosis-promoting Bcl-2 family members are located in the cytoplasm; however, they activate apoptotic signals via external stimuli; subsequently, these signals are transferred to mitochondria, leading to changes in mitochondrial membrane permeability [33]. These changes prompt the transfer of cytochrome $\mathrm{C}$ (CytoC) from the inner mitochondrial membrane to the cytosol [34]. Caspase-9 acts as an apoptosis activator that plays a key role in the mitochondrial apoptotic pathway [35]. Caspase-9 is located upstream of the cascade reaction, forming an active complex with an apoptosis protease activator and CytoC [36]. Subsequently, the complex activates downstream apoptosis-inducing caspase-3, which hydrolyses apoptosis-inhibiting proteins and repair-related molecules, ultimately activating mitochondrial pathway-mediated apoptosis [37]. The anti-apoptotic factor Bcl-2 suppresses caspase activation in the aforementioned process, reducing Cyto $\mathrm{C}$ release. In these processes, $\mathrm{Bcl}-2$ can inhibit apoptosis [38].

In summary, following UV irradiation at $10 \mathrm{~J} / \mathrm{cm}^{2}$, SOD and GSH-Px activity in the photoaging group was decreased. In contrast, the content of ROS and MDA and the protein expression levels of IL-10 and TNF-a in the photoaging group were increased. However, after PE treatment, SOD and GSH-Px activity was 
increased, and ROS, MDA, IL-10, and TNF-a expression levels were decreased. These results suggest that $\mathrm{PE}$ can effectively increase the activity of SOD and GSH-Px, remove oxygen free radicals from the cell, and inhibit lipid peroxidation. Furthermore, GSH-Px can reduce the effects of UV radiation in cells by reducing the production of inflammatory IL-10 and TNF-a. Additionally, the western blot results demonstrated that PE upregulates the expression level of the anti-apoptotic protein $\mathrm{Bcl}-2$ and downregulated caspase-3, caspase-9, and Bax expression. These results suggest that PE effectively protects $\mathrm{HaCaT}$ cells against photoaging damage through a mechanism that involves mitochondrial apoptotic pathways. Thus, PE may be utilized as a new natural sunscreen agent to prevent skin damage triggered by UV (Fig. 7).

\section{Conclusions}

Our study shows for the first time that PE can inhibit UV-induced apoptosis through the mitochondrial pathway, which is mainly regulated by reducing ROS and MDA content, increasing the activity of SOD and GSH-Px, and inhibiting the inflammatory response and mitochondrial-mediated apoptosis signalling. These findings indicate that PE can effectively prevent UV-induced cell damage.

\section{Abbreviations}

PE: pearl extract; UV: ultraviolet; SOD: superoxide dismutase; GSH-Px: glutathione peroxidase; MAD: malondialdehyde; ROS: reactive oxygen species; TNF-a: tumor necrosis factor-a; IL-10: interleukin-10

\section{Declarations}

\section{Ethics approval and consent to participate}

Not applicable.

\section{Consent for publication}

Not applicable.

\section{Availability of data and materials}

We declared that materials described in the manuscript, including all relevant raw data, will be freely available to any scientist wishing to use them for non-commercial purposes,

\section{Competing interests}

The authors declare that they have no competing interests.

\section{Funding}

None 
Authors' contributions

ZC designed the experiments and wrote the paper. JW, AY, LZ, and YL performed the experiments. JM, MX, and XS analyzed the data.

\section{Acknowledgements}

The study was supported by the Zhejiang Osmum Group Deqing Biotechnology Co., Ltd., in Huzhou, China

\section{References}

1. Guo Q, Fang S, Zeng FQ, Li BY, Zhu XJ, Tan GZ. Establishment and optimization of two-dimensional gel electrophoresis profiles of proteome from human keratinocytes. China $\mathrm{J}$ Mod Med. 2008;18:3453-3455+3459.

2. Dou M, Chu X, Zhang J, Chen XH, Wang YJ, Shao BQ, Wang CB. Polypeptide from chlamys farreri protect $\mathrm{HaCaT}$ cells from single UVA induced oxidative dam ages. Chin Pharmacol Bull. 2006;22:420-3.

3. Wang HY, Zeng YY, Wang T, Xing FY, Zhao JX, Ji YH. Effects of ultraviolet on mitochondrial functions and apoptosis in HaCaT cells. Chin J Pathophysiol. 1989;22:1020-3.

4. Chen F, Tang Y, Sun YJ, Veeraraghavan VP, Mohan SK, Cui CX. 6-shogaol, active constituents of ginger prevents UVB radiation mediated inflammation and oxidative stress through modulating NrF2 signaling in human epidermal keratinocytes (HaCaT cells). J Photochem Photobiol B. 2019;197:111518.

5. Narayanapillai S, Agarwal C, Tilley C, Agarwal R. Silibinin is a Potent Sensitizer of UVA Radiationinduced Oxidative Stress and Apoptosis in Human Keratinocyte HaCaT Cells. Photochem Photobiol. 2012;88:1135-40.

6. Li JL, Liu N, Chen XH, Sun M, Wang CB. Inhibition of UVA-induced apoptotic signaling pathway by polypeptide from Chlamys farreri in human HaCaT keratinocytes. Radiat Environ Biophys. 2007;46:263-8.

7. Cross SE, Innes B, Roberts MS, Tsuzuki T, Robertson TA, McCormick P. Human skin penetration of sunscreen nanoparticles: in-vitro assessment of a novel micronized zinc oxide formulation. Skin Pharmacol Physiol. 2007;20:148-54.

8. He Z, Zhang L, Zhuo C, Jin F, Wang Y. Apoptosis inhibition effect of Dihydromyricetin against UVAexposed human keratinocyte cell line. J Photochem Photobiol B. 2016;161:40-9.

9. Li JM, Xu YM, Chen QY, Qi YH, Zhang N. Protective effects of UVA induced photoaging in HaCaT cell by Eucommia ulmoides. Chin J Aesthet Med. 2010;19:1316-23.

10. Han ZW, Wang MZ, Wang LY, Long XU, Chen XH, Han YT. Study on Inhibitory Effects of Rose Water on Ultraviolet-induced Apoptosis of HaCaT Cells. China Pharm. 2013;24:592-5. 
11. Li M, Lin XF, Lu J, Zhou BR, Luo D. Hesperidin ameliorates UV radiation-induced skin damage by abrogation of oxidative stress and inflammatory in HaCaT cells. J Photochem Photobiol B. 2016;165:240-5.

12. Lin J, Wei MC, Mo MY. Analysis of the Clinical Application and Compatibility of Pearl. J Basic Chin Med. 2016;22:1691-1703.

13. Yang AQ, Shen YQ, Zhang LH, Mo JH, Chen ZX, Wang J. Study on the Skin Care Functions of Active Ingredients in Pearl Extractive. Flavour Fragr Cosmet. 2016;01:58-61.

14. Yang YL, Chang $\mathrm{CH}$, Huang CC, Liu HW. Anti-inflammation and anti-apoptosis effects of pearl extract gel on UVB irradiation HaCaT cells. Biomed Mater Eng. 2015;26 Suppl 1:S139-45.

15. Zhou DX, Wu SL. Anti-inflammation and Antioxidation of Pearl Water Extract. J Zhe Jiang Coll TCM. 2001;25:41-3.

16. Yang AQ, Wang J, Zhang LH, Mo JH, Chen ZX, Shen YQ. Lighting Effect of Pearl Extract on Melanocytes in Vitro. Pharm Biotechnol. 2016;23:146-9.

17. Marks R. Seeing through the Stratum Corneum. Keio J Med. 2000;49:80-3.

18. Svobodová A, Zdařilová A, Mališková J, Mikulková H, Walterová D, Vostalová J. Attenuation of UVAinduced damage to human keratinocytes by silymarin. J Dermatol Sci. 2006;46:21-30.

19. D'Arcy MS. Cell death: A review of the major forms of apoptosis, necrosis and autophagy. Cell Biol Int. 2019;43:582-92.

20. Virag L, Jaén RI, Regdon Z, Boscá L, Prieto P. Self-defense of macrophages against oxidative injury: Fighting for their own survival. Redox Biol. 2019;26:101261.

21. Takasawa R, Nakamura H, Mori T, Tanuma S. Differential apoptotic pathways in human keratinocyte HaCaT cells exposed to UVB and UVC. Apoptosis. 2005;10:1121-30.

22. Svobodová A, Walterová D, Vostalova J. Ultraviolet light induced alteration to the skin. Biomed Pap Med Fac Univ Palacky Olomouc Czech Repub. 2006;150:25-38.

23. Brand RM, Wipf P, Durham A, Epperly MW, Greenberger JS, Falo LD. Targeting Mitochondrial Oxidative Stress to Mitigate UV-Induced Skin Damage. Front Pharmacol. 2018;9:920.

24. Likidlilid A, Patchanans N, Peerapatdit T, Sriratanasathavorn C. Lipid peroxidation and antioxidant enzyme activities in erythrocytes of type 2 diabetic patients. J Med Assoc Thai. 2010;93:682-93.

25. Svobodová AR, Galandáková A, Sianská J, Doležal D, Ulrichová J, Vostalová J. Acute exposure to solar simulated ultraviolet radiation affects oxidative stress-related biomarkers in skin, liver and blood of hairless mice. Biol Pharm Bull. 2011;34:471-9.

26. Marionnet AV, Chardonnet Y, Viac J, Schmitt D. Differences in responses of interleukin-1 and tumour necrosis factor a production and secretion to cyclosporin-A and ultraviolet B-irradiation by normal and transformed keratinocyte cultures. Exp Dermatol. 1997;6:22-8.

27. Frank S, Kämpfer H, Wetzler C, Stallmeyer B, Pfeilschifter J. Large induction of the chemotactic cytokine RANTES during cutaneous wound repair: a regulatory role for nitric oxide in keratinocytederived RANTES expression. Biochem J. 2000;347 Pt 1:265-73. 
28. Di Girolamo N, Wakefield D, Coroneo MT. UVB-mediated induction of cytokines and growth factors in pterygium epithelial cells involves cell surface receptors and intracellular signaling. Invest Ophthalmol Vis Sci. 2006;47:2430-7.

29. Wang YQ, Chen QY, Li JM, Zhang N. Regulation of chlorogenic acid on expression of tumour necrosis factor- $a$ and interleukin- 6 in HaCat cells damaged by ultroviolet. Chin J Pharmacol Toxicol. 2014;28:63-7.

30. Tait SW, Green DR. Mitochondria and cell death: outer membrane permeabilization and beyond. Nat Rev Mol Cell Biol. 2010;11:621-32.

31. Kaufmann T, Schlipf S, Sanz J, Neubert K, Stein R, Borner C. Characterization of the signal that directs $B c l-x(L)$, but not Bcl-2, to the mitochondrial outer membrane. J Cell Biol. 2003;16:53-64.

32. Chandra J, Samali A, Orrenius S. Triggering and modulation of apoptosis by oxidative stress. Free Radic Biol Med. 2000;29:323-33.

33. Antonsson B. Mitochondria and the Bcl-2 family proteins in apoptosis signaling pathways. Mol Cell Biochem. 2004;256-257:141-55.

34. Chang HY, Yang X. Proteases for cell suicide: functions and regulation of caspases. Microbiol Mol Biol Rev. 2000;64:821-46.

35. Würstle ML, Laussmann MA, Rehm M. The central role of initiator caspase-9 in apoptosis signal transduction and the regulation of its activation and activity on the apoptosome. Exp Cell Res. 2012;318:1213-20.

36. Bhattacharya S, Ray RM, Johnson LR. Cyclin-dependent kinases regulate apoptosis of intestinal epithelial cells. Apoptosis. 2014;19:451-66.

37. Sinha K, Das J, Pal PB, Sil PC. Oxidative stress: the mitochondria-dependent and mitochondriaindependent pathways of apoptosis. Arch Toxicol. 2013;87:1157-80.

38. Shimizu H, Banno Y, Sumi N, Naganawa T, Kitajima Y, Nozawa Y. Activation of p38 mitogen-activated protein kinase and caspases in UVB-induced apoptosis of human keratinocyte HaCaT cells. J Invest Dermatol. 1999;112:769-74.

\section{Table}

\section{Table 1. Real-time PCR primers}


Primer pairs

TNF- $\alpha$ 5'-CTGCTGCACTTTGGAGTGAT-3'

5'-AGATGATCTGACTGCCTGGG-3'

IL-10 5'-GAACCAAGACCCAGACATC-3'

5'-GCATTCTTCACCTGCTCCAC-3'

Actin 5'-CATGTACGTTGCTATCCAGGC-3'

5'-CTCCTTAATGTCACGCACGAT3'

Figures 


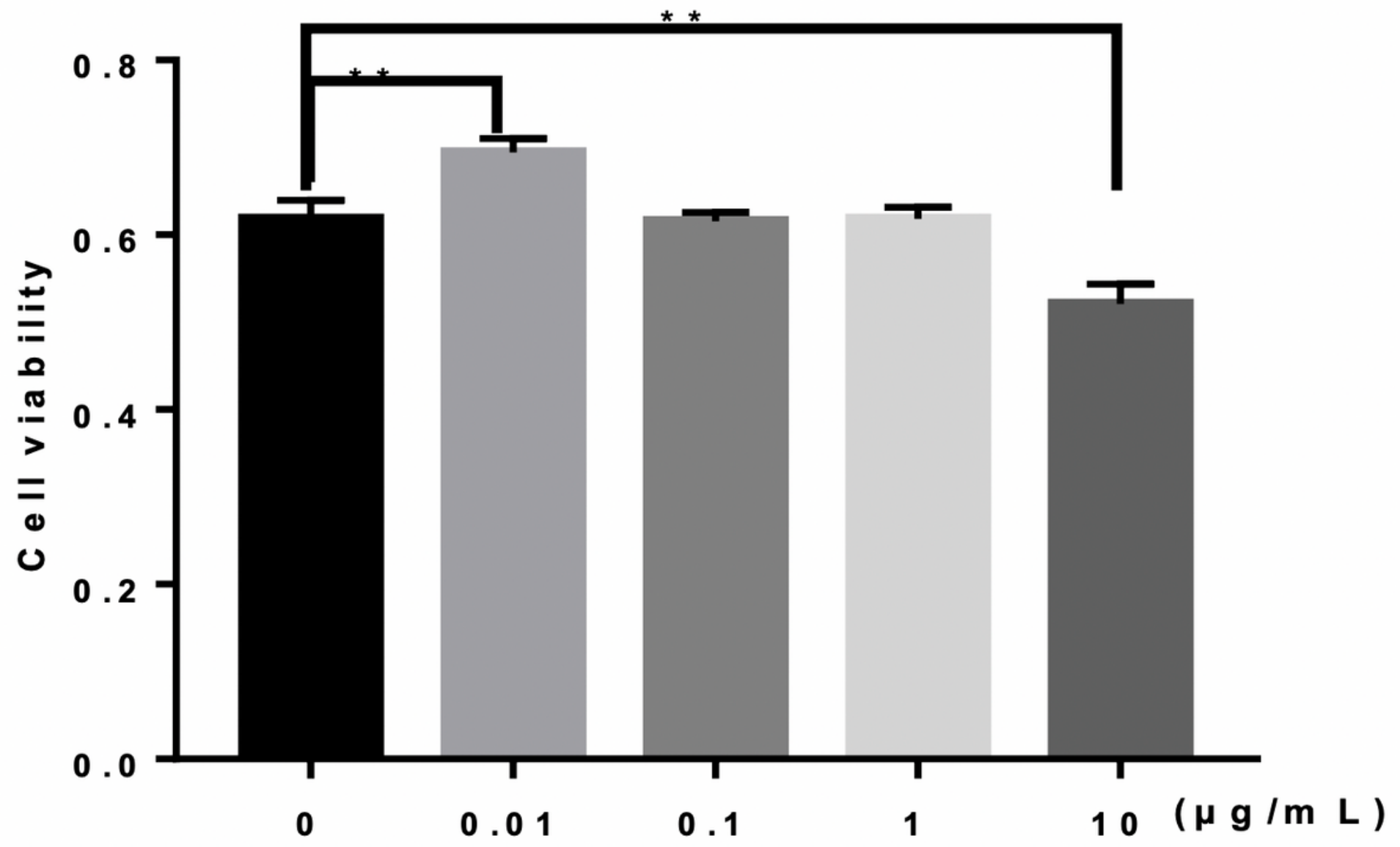

Figure 1

Effect of pearl extract (PE) on proliferation rate of normal HaCaT cells. Cell viability was determined by a CCK8 assay. HaCaT cells were treated with PE $(0-10 \mu \mathrm{g} / \mathrm{mL})$ for $48 \mathrm{~h}$. Data are expressed as mean \pm SD. The experiments were performed at least three times independently. ${ }^{*} \mathrm{P}<0.01$ indicates significant differences between experimental and control groups 


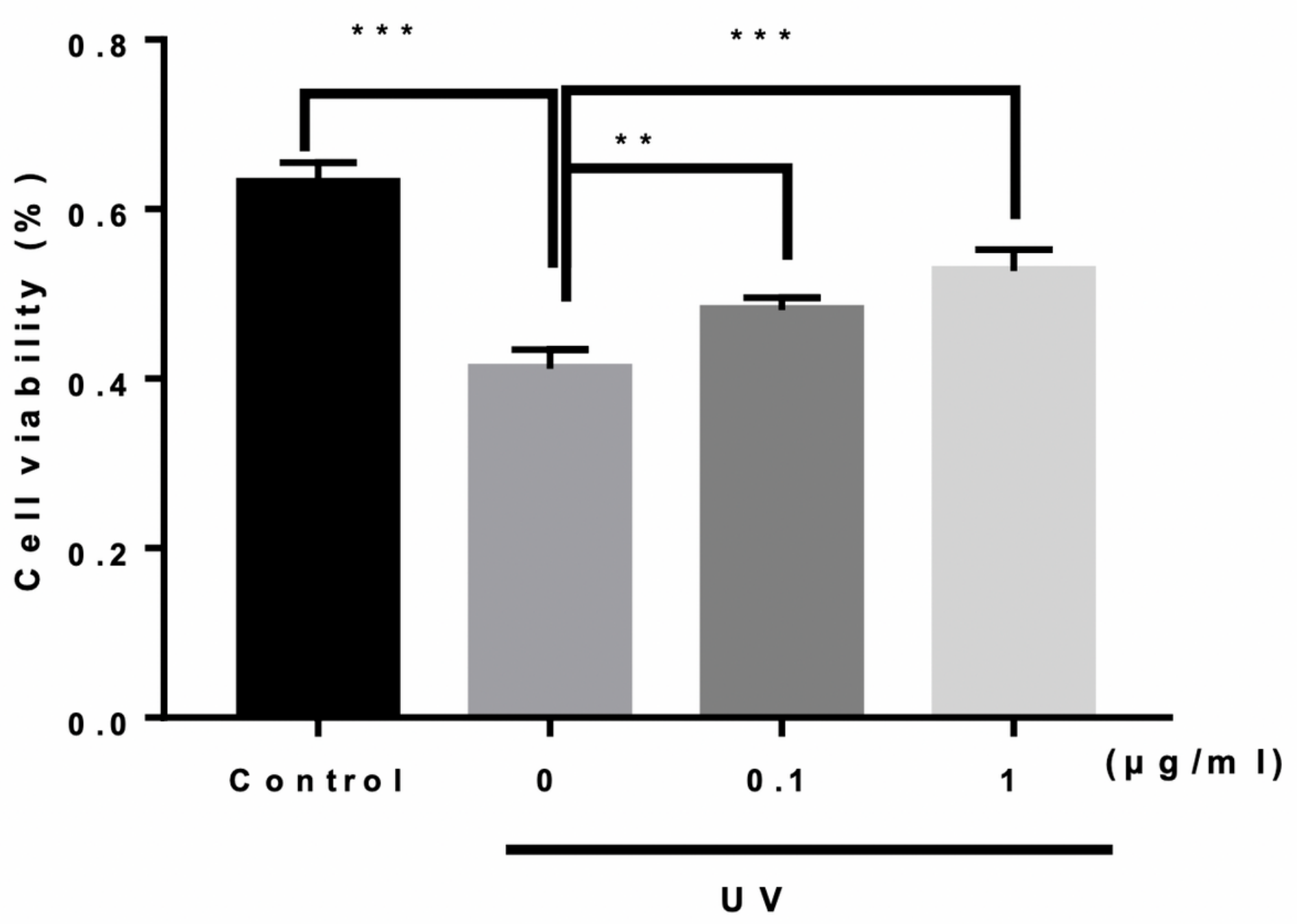

Figure 2

Effects of different treatment conditions on viability of UV-irradiated HaCaT cells. Cell viability was determined by a CCK8 assay. HaCaT cells were treated with pearl extract (PE; $0,0.1$, and $1 \mu \mathrm{g} / \mathrm{mL}$ ) for 48 h. The cells were exposed to $10 \mathrm{~J} / \mathrm{cm} 2 \mathrm{UV}$, and the control group was sham-irradiated by covering with tin foil. Data are expressed as mean \pm SD. The experiments were performed at least three times independently. ${ }^{*} \mathrm{P}<0.01$ and ${ }^{* \star *} \mathrm{P}<0.01$ indicate significant differences between experimental and control groups 

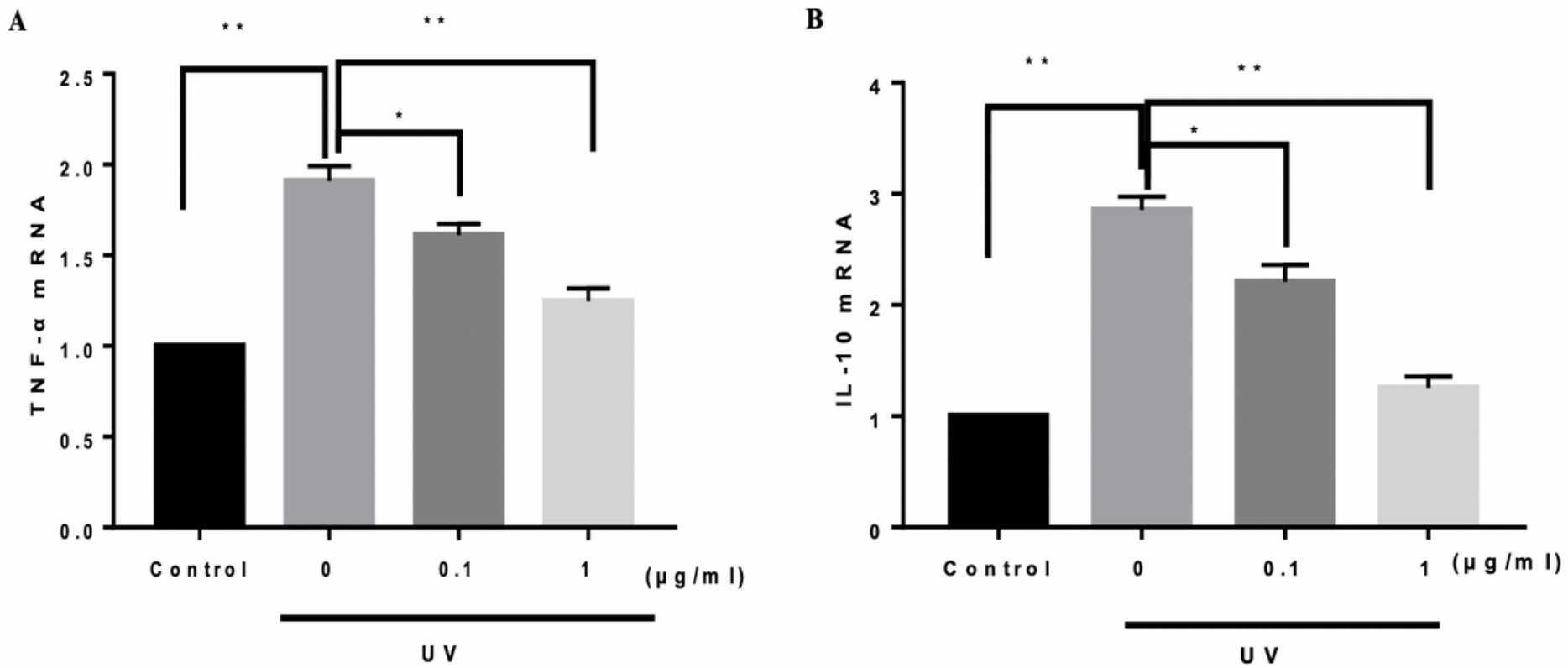

Figure 3

Effect of pearl extract (PE) on mRNA expression. (a) Tumor necrosis-alpha (TNF-a) mRNA expression level. (b) Interleukin (IL)-10 mRNA expression level. Data are expressed as mean \pm SD. The experiments were performed at least three times independently. ${ }^{*} \mathrm{P}<0.05$ and ${ }^{*} \mathrm{P}<0.01$ indicate significant differences between photoaging and other groups
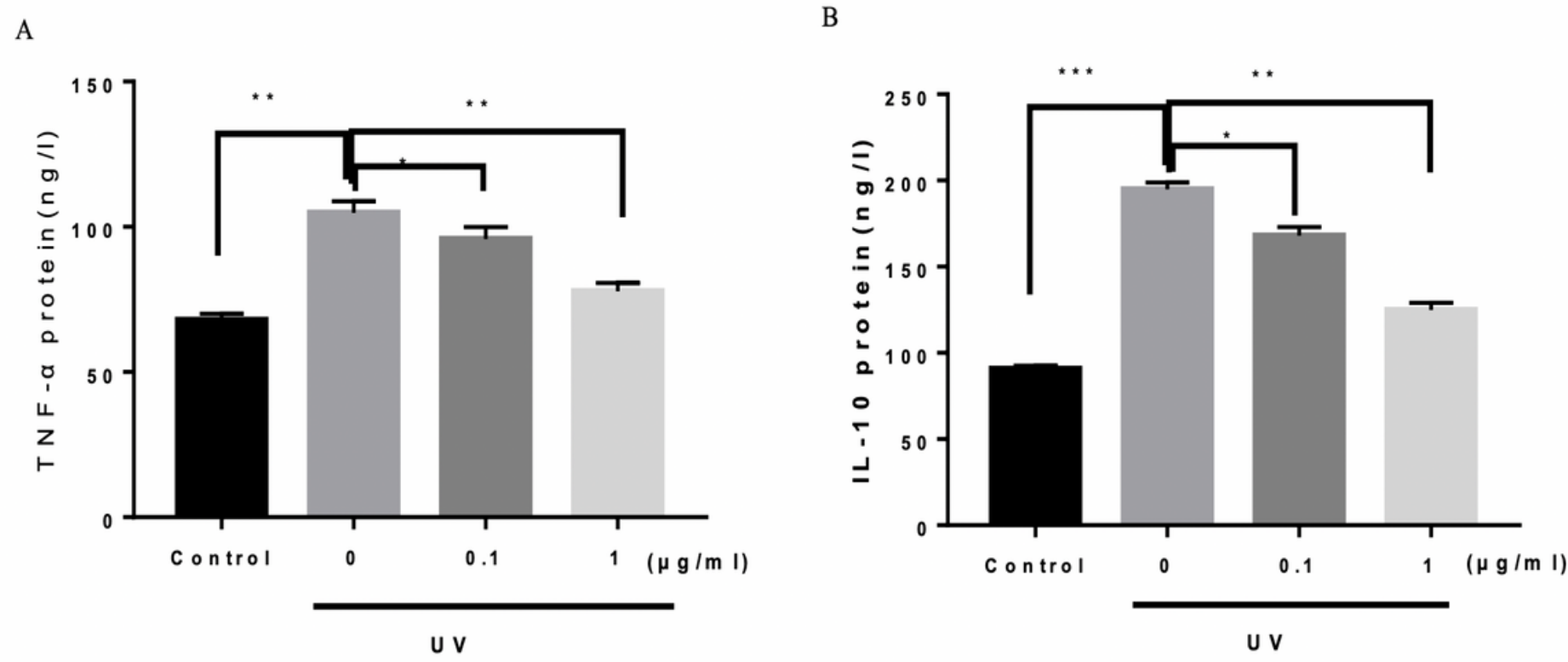

Figure 4

Effect of pearl extract (PE) on tumor necrosis-alpha (TNF-a) and interleukin (IL)-10 content in HaCaT cell supernatant. TNF-a protein expression (a) and IL-10 protein expression (b). Data are expressed as mean \pm 
SD. The experiments were performed at least three times independently. ${ }^{*} P<0.05, * \star P<0.01$, and ${ }^{\star * \star} P<$ 0.01 indicate significant differences between photoaging and other groups

A

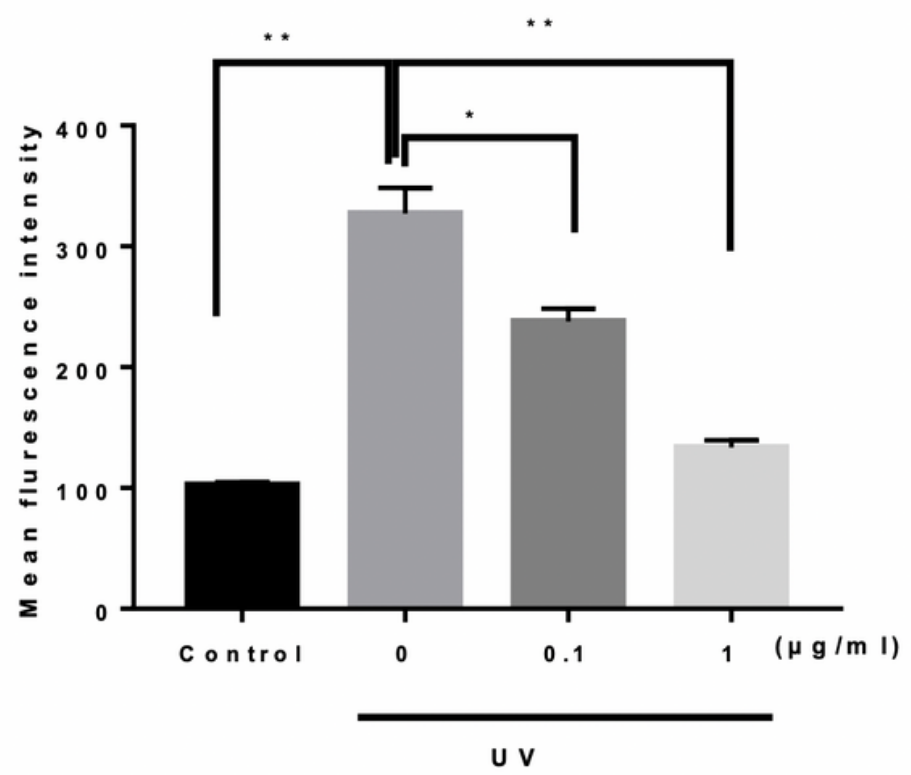

C

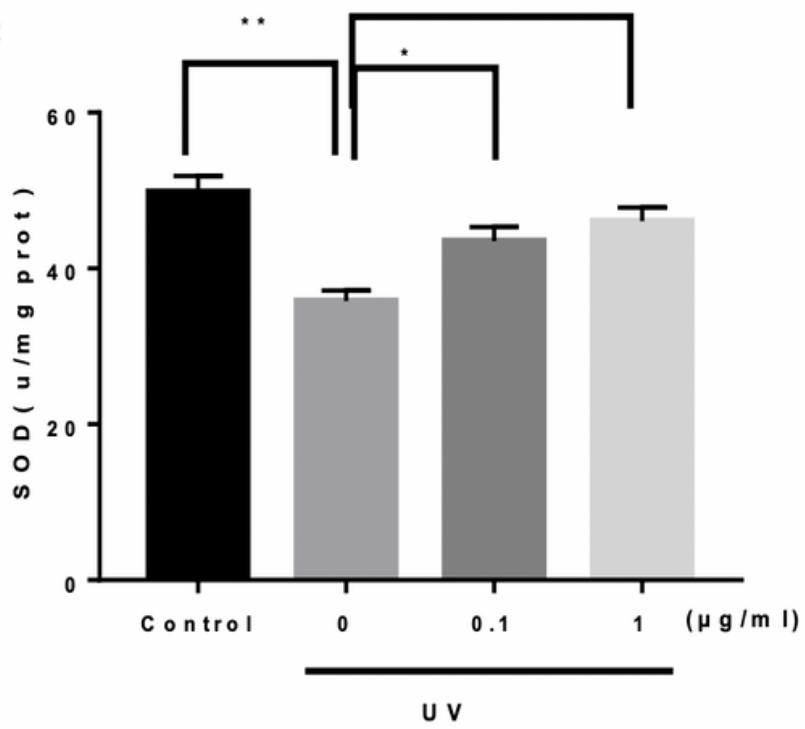

B
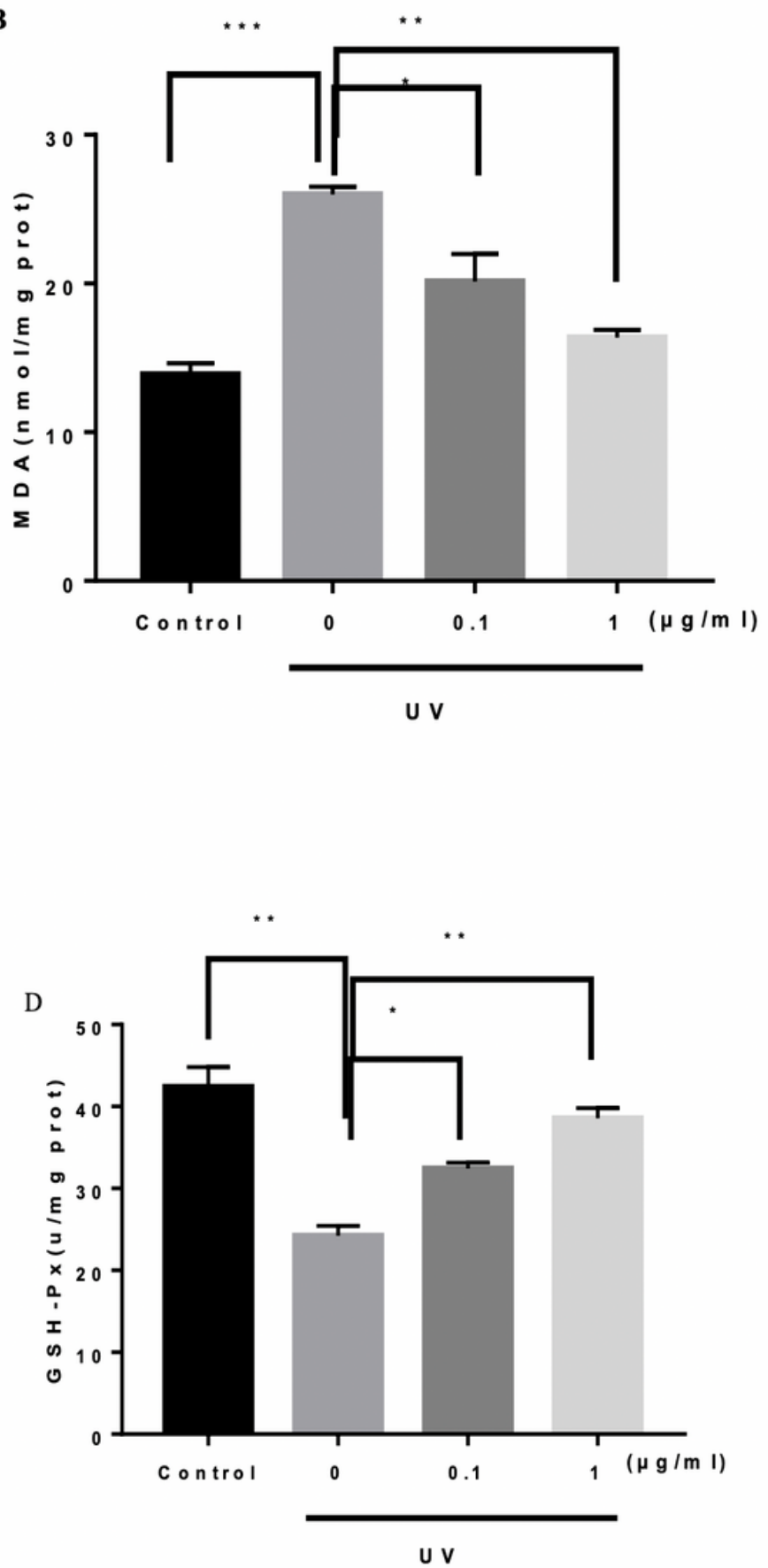

Figure 5

Effects of pearl extract (PE) on antioxidant index in HaCaT cells. Reactive oxygen species (ROS) levels (a), malondialdehyde (MDA) levels (b), superoxide dismutase (SOD) activity (c), and glutathione peroxidase (GSH-Px) activity (d). Data are expressed as mean \pm SD. The experiments were performed at least three times independently. ${ }^{*} P<0.05,{ }^{*} \mathrm{P}<0.01$, and ${ }^{* \star *} \mathrm{P}<0.01$ indicate significant differences between photoaging and other groups 
A

caspase-3

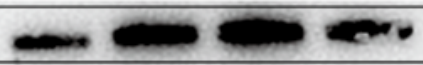

caspase-9

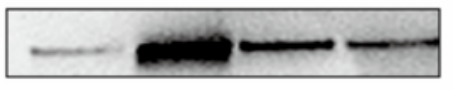

Bax

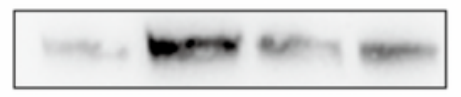

Bcl-2

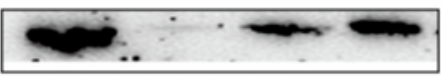

$\beta$-actin

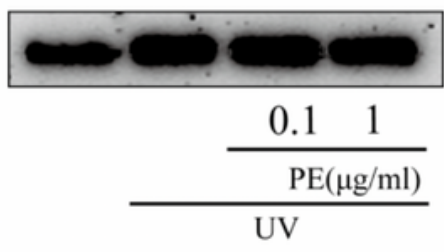

B

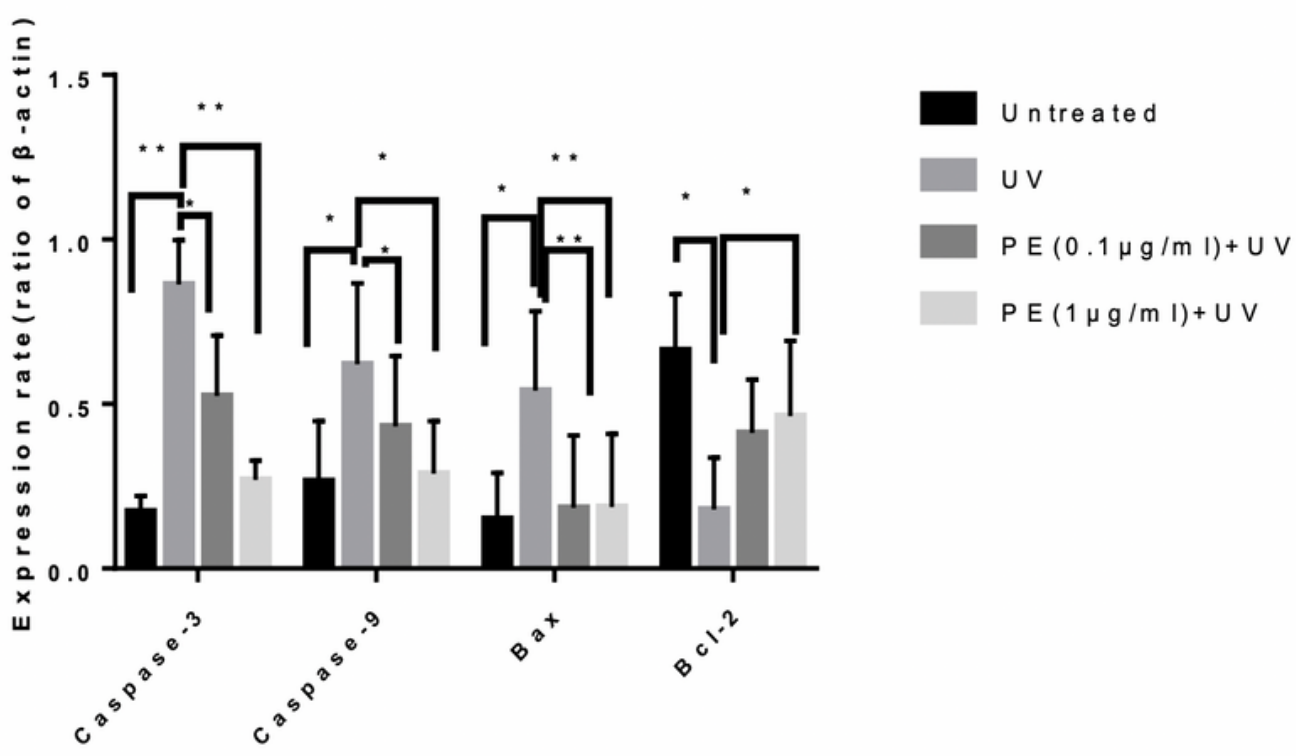

\section{Figure 6}

Effect of pearl extract (PE) on UV-induced protein expression. Caspase-3, caspase-9, Bax, and Bcl-2 in HaCaT cells, as determined by western blotting (a) and band densitometry analysis (b). Data are expressed as mean \pm SD. The experiments were performed at least three times independently. ${ }^{*} \mathrm{P}<0.05$ and $* * P<0.01$ indicate significant differences between photoaging and other groups 


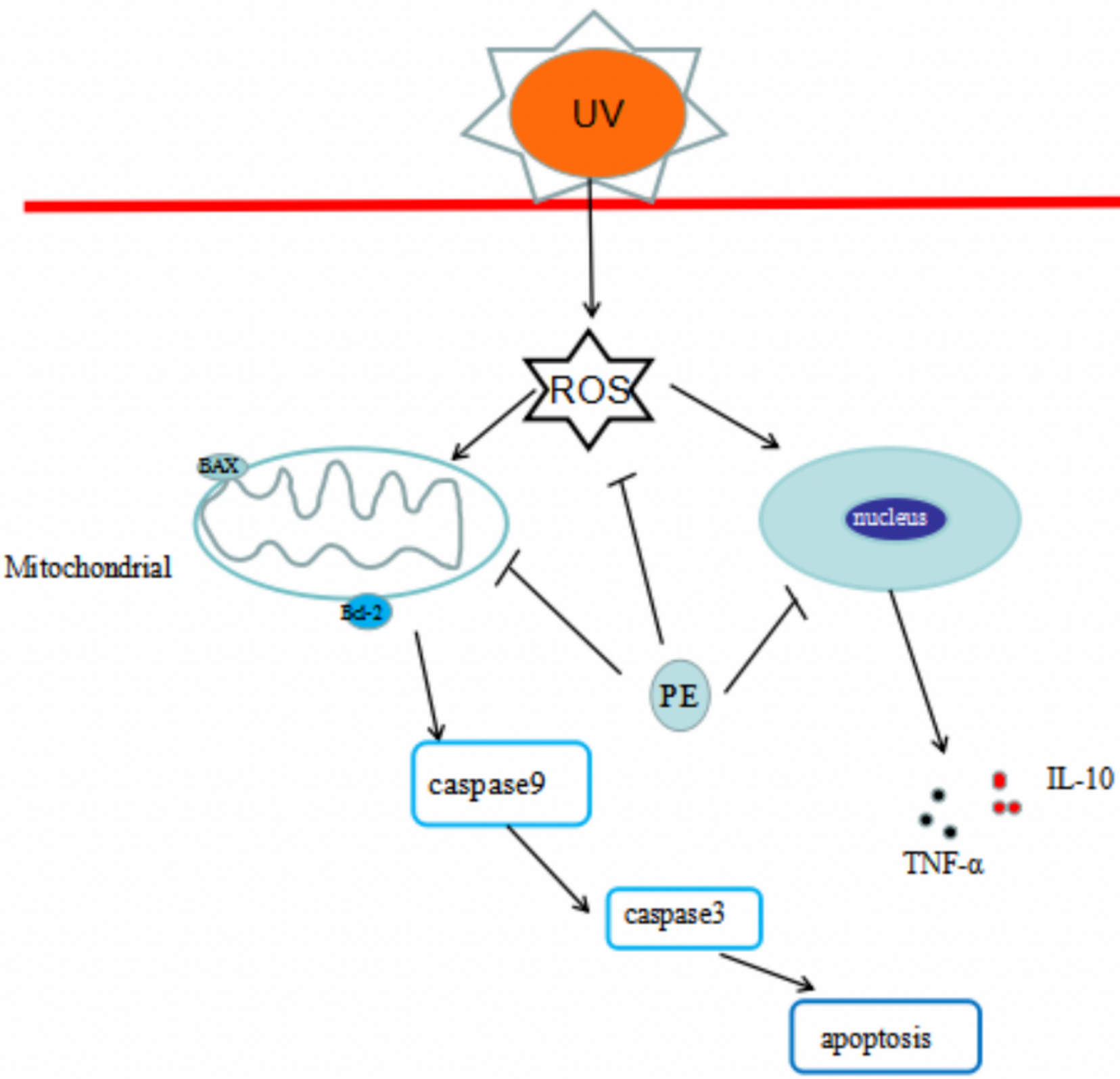

Figure 7

Schematic illustration of photoaging-protective properties of pearl extract 